\title{
Analysis of Long-term Stored Plasma Samples for Investigation into the Pathophysiology of Vibration- induced White Finger: Preliminary Results
}

\author{
Yoshinao KAWANO ${ }^{1}$, Hossain Md. MAHBUB ${ }^{1}$, Ryosuke HASE ${ }^{1}$, \\ Tatsuo SAKAMOTO ${ }^{2}$ and Noriaki HARADA ${ }^{1 *}$ \\ ${ }^{1}$ Department of Hygiene, Yamaguchi University Graduate School of Medicine, Japan \\ ${ }^{2}$ Department of Health and Sport Sciences, Chukyo University, Japan
}

Received February 25, 2014 and accepted August 4, 2014

Published online in J-STAGE September 13, 2014

\begin{abstract}
Blood samples were collected $25 \mathrm{yr}$ ago from hand-arm vibration syndrome patients with vibration-induced white finge/VWF (VWF+ group) and without it (VWF- group), and healthy controls ( $\mathrm{n}=12$ in each group), and stored at $-80^{\circ} \mathrm{C}$. The subjects provided venous blood twice: at baseline, and after cold exposure at $7^{\circ} \mathrm{C}$ for $25 \mathrm{~min}$. Blood specimens were analyzed for plasma endothelin-1 (ET-1) by an enzyme-linked immunosorbent assay. Baseline concentration of plasma ET-1 was found to be significantly larger in the VWF- group than the control group, whereas no such difference was observed for the VWF+ group. However, the \%change was larger in the VWF+ group $(107.73 \pm 30.49 \%)$ than the other two groups, and more subjects in the VWF+ group showed the maximum increase in ET-1 than the other two groups. In conclusion, ET-1 appears to have a role in the pathophysiology of VWF.
\end{abstract}

Key words: Cold test, Plasma, Endothelin, White finger, Hand-arm vibration

Prolonged occupational exposure to hand-transmitted vibration can lead to the development of hand-arm vibration syndrome (HAVS), a well-recognized health disorder in regions with temperate climate ${ }^{1,2)}$. HAVS includes vascular, neural and musculoskeletal disorders of the upper extremities, especially of the hands. The costs for compensation, treatment and other indirect costs associated with HAVS still remain very high.

Depending on the type and duration of exposure, the prevalence of vascular symptoms in HAVS can be as high as $70 \%$ or more ${ }^{3)}$. Vibration-induced white finger (VWF), a secondary type of Raynaud's phenomenon is the most prominent vascular component of HAVS. The pathophysi-

*To whom correspondence should be addressed. E-mail: harada@yamaguchi-u.ac.jp

(C)2014 National Institute of Occupational Safety and Health ological mechanism for vascular injuries in HAVS is multifactorial and highly complex. Regarding this vascular disorder, organic (narrowing of arterial lumen with medial smooth muscle hypertrophy) and functional factors (increased sympathetic activity with vasoconstrictor response to cold, endothelin-1 (ET-1) and plasma catecholamine release, increased $\alpha_{2}$-adrenoreceptor reactivity, and decreased vasodilatation relating to inadequate release of nitric oxide and calcitonin gene-related peptide etc.) have been pointed out ${ }^{1,4)}$.

Recently, blood biomarkers are increasingly being used in the evaluation of various occupational diseases. Analysis of blood biomarkers with a high degree of validity and reliability can be useful in understanding the underlying pathophysiology and assessing the severity of a disorder. However, the number of studies investigating the changes in hormonal and immunological parameters associated 
Table 1. Demographic characteristics of the study population

\begin{tabular}{lcrc}
\hline \multicolumn{1}{c}{ Characteristics } & VWF + & VWF- & Control $^{\#}$ \\
\hline Age (yr) & $56.7 \pm 5.2$ & $57.3 \pm 4.6$ & $56.3 \pm 4.9$ \\
Smoking currently & $7(58.3 \%)$ & $9(75.0 \%)$ & $7(58.3 \%)$ \\
Current alcohol use & $8(66.7 \%)$ & $9(75.0 \%)$ & $11(91.7 \%)$ \\
Vibration exposure (yr) & $16.4 \pm 7.6$ & $16.3 \pm 5.0$ & - \\
Years after ceasing exposure to HTV & $6.1 \pm 5.1$ & $5.7 \pm 4.9$ & - \\
\hline
\end{tabular}

Values are shown as mean $\pm \mathrm{SD}$ except for smoking and alcohol use shown as $\mathrm{n}$ (column\%)

\#Six of the control subjects were exposed to non-regular non-occupational vibration

with VWF is very limited. The purpose of this study was to analyze the blood samples of HAVS patients for various potential biomarkers associated with VWF including ET1, C-reactive protein (CRP), substance $\mathrm{P}$, von Willebrand factor (VWF) and calcitonin gene-related peptide (CGRP). We have completed the measurement of plasma ET-1 and the relevant data are being presented in the current paper. The blood samples were obtained during a large-scale survey conducted in four areas of western Japan in the period October 1987 to March 1988. The aim of that survey was to investigate the sympathetic and hormonal responses to cold exposure in subjects with HAVS. The findings of that work have been published elsewhere ${ }^{5-7)}$. The current study to analyze the blood samples of HAVS patients for VWF- related biomarkers has been approved by the institutional review board of Yamaguchi University Hospital (No. H25-131).

The survey included HAVS patients with (VWF+ group, $\mathrm{n}=86$ ) and without vibration-induced white finger (VWF- group, $n=97)$, and healthy controls $(n=84)^{6}$. The diagnosis of HAVS was based on a medical interview: subjects in the VWF+ group had a positive history of finger blanching (white finger) attacks, a few times per week during the previous winter; subjects in the VWF- group did not have a history of white finger but had other symptoms HAVS, such as numbness or pain ${ }^{5-7)}$. The majority of the HAVS patients used chain-saws and rock drills. The participants in the control group were associated with various occupations without regular use of hand-held vibrating power tools. The study subjects were selected according to the following criteria: no current/past history of injury to the upper extremities, peripheral neuropathy or connective tissue disorders, diabetes or peripheral vascular diseases (of non-VWF origin for the patients) likely to influence the test results.

As an adjunct to the survey, the plasma extracted from the whole blood samples by centrifugation was stored at $-80^{\circ} \mathrm{C}$ for future analysis. Blood samples were collected twice: before and after the cold challenge. After arrival to the experiment room, the subjects wore two pieces of clothing on the upper and lower half of the body and were acclimatized to the room temperature $\left(25 \pm 1^{\circ} \mathrm{C}\right)$ for a period of $30 \mathrm{~min}$ in a temperature-controlled room, seated comfortably on a chair. After 25 min of acclimatization, cubital venous blood was drawn from the study subjects. Then the subjects moved to the cold room (room temperature, $7 \pm 1^{\circ} \mathrm{C}$ ) and kept sitting there for further $30 \mathrm{~min}$. The second blood sample was collected at 25th min of cold exposure. Drawing of blood was performed between 9:30 am and 12:30 pm to avoid any influences of the circadian rhythm. The subjects were instructed to refrain from taking any medication for $7 \mathrm{~d}$ prior to the experiment.

All measurements were performed blindly. Plasma ET-1 was measured by a commercially available enzymelinked immunosorbent assay (ELISA) (Quantikine, R\&D Systems, USA). All samples (standard, control and blank) were assayed in duplicate according to the manufacturer's instructions. The absorbance of the samples was measured at $450 \mathrm{~nm}$ with $570 \mathrm{~nm}$ as the reference.

The data were analyzed using Wilcoxon signed-ranks test for two-related samples with Bonferroni corrections for multiple comparisons as appropriate. The difference between the groups for current smoking status and current alcohol use was investigated by using Fisher's exact test. The Statistical analyses were performed with statistical software SPSS version 16.0. Statistical significance was considered at a two-sided $p<0.05$.

After individual matching (according to age), the data for a total of 36 subjects (12 subjects in each of the VWF+, VWF-, and control groups) could be included in the analysis. Baseline demographic characteristics did not differ between the three groups (Table 1). Out of the 12 control subjects, $6(50 \%)$ were exposed to non-regular vibration with a vibration exposure of $9.00 \pm 6.03 \mathrm{yr}$ and $410.00 \pm 550.45 \mathrm{~h}$.

Table 2 shows the plasma ET-1 concentrations of the 
Table 2. Response in plasma ET-1 levels to cold challenge ( $n=12$ in each group)

\begin{tabular}{lccc}
\hline \multirow{2}{*}{ Group } & \multicolumn{3}{c}{ Plasma ET-1 $(\mathrm{pg} / \mathrm{ml})$} \\
\cline { 2 - 4 } & Baseline & After exposure & \%change \\
\hline VWF+ & $0.46 \pm 0.13$ & $0.48 \pm 0.17$ & $107.73 \pm 30.49$ \\
VWF- & $0.53 \pm 0.08$ & $0.54 \pm 0.13$ & $102.20 \pm 18.12$ \\
Control & $0.44 \pm 0.07$ & $0.46 \pm 0.09$ & $104.45 \pm 11.46$ \\
\hline
\end{tabular}

Values are shown as mean $\pm \mathrm{SD}$

three groups at baseline and after the cold challenge. The baseline ET-1 concentration in the VWF- group was significantly greater compared with the control group $(0.53 \pm$ $0.08 \mathrm{pg} / \mathrm{ml}$ vs. $0.44 \pm 0.07 \mathrm{pg} / \mathrm{ml}$, respectively; $p=0.036$ ), whereas no such difference was observed for the VWF+ group $(0.46 \pm 0.12 \mathrm{pg} / \mathrm{ml})$.

After the cold challenge, there was a small, not significant increase in average plasma ET-1 concentrations in all groups (Table 2). The \%change was larger in the VWF+ group $(107.73 \pm 30.49 \%)$ than the other two groups $(102.20$ $\pm 18.12 \%$ and $104.45 \pm 11.46 \%)$. More subjects in the VWF + group showed an increase in ET-1 than the other two groups, after the cold challenge (results not shown). Among the $12 \mathrm{VWF}+$ patients included in the analyses, 3 (25\%) had a more than $140 \%$ change in ET-1 in contrast to $1(8.3 \%)$ and none in the VWF- and control groups, respectively.

In recent years, it has become increasingly difficult to obtain blood specimens from typical cases of HAVS as the responses in plasma biomarkers induced by cold provocation may be confounded by the fact that such patients also usually suffer from other diseases like hypertension, diabetes mellitus influencing the peripheral circulation. Therefore, we decided to use the blood samples collected 25 years ago from more or less typical cases of HAVS.

Some earlier studies demonstrated an association between vibration exposure and plasma concentrations of ET- ${ }^{8,9)}$. It has been suggested that vibration-induced severe shear stress in arterial walls can cause endothelial damage or dysfunction with an increased release of ET$1^{10,11)}$. Therefore, an elevation in endothelin levels may reflect endothelial dysfunction and damage ${ }^{12)}$. In our study, baseline concentrations of ET-1 were lower in the VWF+ group than in the exposed (VWF-) group. In a study Palmer and Mason (1996) reported lower baseline concentrations of serum endothelin (ET1-21) in the patient group than in the exposed group without any vascular symptoms or unexposed controls ${ }^{13}$. In contrast, in the study of Toibana et al., mean plasma ET-1 concentrations were higher in patients with VWF than those without VWF or normal controls ${ }^{8)}$.

In the current study, despite an increasing trend in all groups, cold challenge did not induce any significant change in plasma ET-1 concentrations in any of the groups. In a study, Bovenzi et al. observed a small nonsignificant increase in the salivary ET1-21 concentration in both the controls and the forestry workers after a local cold test ${ }^{10)}$. On the other hand, Palmer and Mason observed a significant increase in ET-1 concentrations in the patient group with VWF compared with the exposed group without VWF or unexposed controls after a cold challenge ${ }^{13)}$. In the study of Palmer and Mason, both hands were immersed into water of $6^{\circ} \mathrm{C}$ for $6 \mathrm{~min}$ and in the study of Bovenzi et al., only one finger was cooled at $10^{\circ} \mathrm{C}$ for $5 \mathrm{~min}$. In contrast, in the current study, the participants were exposed to whole-body cooling in a cold room with a temperature of $7 \pm 1{ }^{\circ} \mathrm{C}$ for $25 \mathrm{~min}$. The methods (local or whole-body) and severity of the cold challenge might be responsible for the observed differences in ET-1 concentrations between the studies. Furthermore, endothelial cells release ET-1 predominantly abluminally towards the vascular smooth muscle cells; only $\sim 20 \%$ of ET- 1 is directed towards the vessel lumen ${ }^{10}$. Therefore, plasma ET-1 levels may be not representative of local production and activity at the interface between endothelium and vascular smooth muscle $^{14)}$. Moreover, relatively greater instability of endothelin concentrations after cold challenge may be also responsible for the observed plasma ET-1 levels in this study ${ }^{13)}$. All these probably explain the fact that we could not clearly demonstrate the specific association between ET-1 and VWF in this study.

The findings of our study should be interpreted in light of some potential limitations. Firstly, the number of matched samples used in this study was limited and it limits the generalizability of the current findings. Secondly, blood samples used in this study were stored at $-80^{\circ} \mathrm{C}$ and may remain as a potential confounding factor to the current findings. ET-1 was first identified in 1988; since then no research work is available that reported the long-term consequences of storage of ET-1. Despite the controversies regarding the long-term consequences of such storage, literature is available that reported the use of blood plasma up to $27 \mathrm{yr}$ after its collection ${ }^{15)}$.

In conclusion, ET-1 appears to have a role in the pathophysiology of VWF. However, whole-body cold challenge used in this study could not induce any significant change in plasma ET-1 concentrations in any of the investigated groups. Future studies with larger samples should be con- 
ducted in order to determine the exact role of ET-1 in the development of vibration-induced vascular injuries and the importance of plasma ET-1 as a potential biomarker in diagnosing the disorder.

\section{References}

1) Harada N, Mahbub MH (2008) Diagnosis of vascular injuries caused by hand-transmitted vibration. Int Arch Occup Environ Health 81, 507-18. [Medline] [CrossRef]

2) Bovenzi M (2012) Epidemiological evidence for new frequency weightings of hand-transmitted vibration. Ind Health 50, 377-87. [Medline] [CrossRef]

3) Letz R, Cherniack MG, Gerr F, Hershman D, Pace P (1992) A cross sectional epidemiological survey of shipyard workers exposed to hand-arm vibration. $\mathrm{Br} \mathrm{J}$ Ind Med 49, 53-62. [Medline]

4) Sakakibara H (1998) Pathophysiology and pathogenesis of circulatory, neurological, and musculoskeletal disturbances in hand-arm vibration syndrome. In: Hand-arm vibration, Pelmear PL and Wasseman DE (Eds.), 45-72, OEM Press, Beverly Farms, Massachusetts.

5) Harada N (1994) Autonomic nervous function of hand-arm vibration syndrome patients. Nagoya J Med Sci 57 Suppl, 77-85. [Medline]

6) Harada N, Nakamoto M, Kohno H, Kondo H, Tanaka M (1990) Hormonal responses to cold exposure in subjects with vibration syndrome. Kurume Med J 37 Suppl, S45-52. [Medline] [CrossRef]

7) Nakamoto M (1990) Responses of sympathetic nervous system to cold exposure in vibration syndrome subjects and age-matched healthy controls. Int Arch Occup Environ Health 62, 177-81. [Medline] [CrossRef]

8) Toibana N, Kanazuka M, Shigekiyo T (1995) High level of plasma thrombomodulin (TM) concentration and correlation with endothelin (ET)-1 in vibration-exposed patients. Cent Eur J Public Health 3 Suppl, 40-2. [Medline]

9) Kohout J, Topolcan O, Bejcková H (1995) The serum level of endothelin in patients with hand-arm vibration syndrome. Cent Eur J Public Health 3 Suppl, 43-4. [Medline]

10) Bovenzi M, D’Agostin F, Rui F, Ambrosi L, Zefferino R (2008) Salivary endothelin and vascular disorders in vibration-exposed workers. Scand J Work Environ Health 34, 133-41. [Medline] [CrossRef]

11) White CR, Haidekker MA, Stevens HY, Frangos JA (2004) Extracellular signal-regulated kinase activation and endothelin-1 production in human endothelial cells exposed to vibration. J Physiol 555, 565-72. [Medline] [CrossRef]

12) Chong AY, Blann AD, Lip GY (2003) Assessment of endothelial damage and dysfunction: observations in relation to heart failure. QJM 96, 253-67. [Medline] [CrossRef]

13) Palmer KT, Mason H (1996) Serum endothelin concentrations in workers exposed to vibration. Occup Environ Med 53, 118-24. [Medline] [CrossRef]

14) Love MP, McMurray JJ (1996) Endothelin in chronic heart failure: current position and future prospects. Cardiovasc Res 31, 665-74. [Medline] [CrossRef]

15) Vickers AJ, Cronin AM, Björk T, Manjer J, Nilsson PM, Dahlin A, Bjartell A, Scardino PT, Ulmert D, Lilja H (2010) Prostate specific antigen concentration at age 60 and death or metastasis from prostate cancer: case-control study. BMJ 341, c4521. [Medline] [CrossRef] 